\title{
Influences of InGaP Conical Frustum Nanostructures on the Characteristics of GaAs Solar Cells
}

\author{
Nguyen Dinh Lam, Youngjo Kim, Kangho Kim, and Jaejin Lee \\ Department of Electrical and Computer Engineering, Ajou University, Suwon 443-749, Republic of Korea \\ Correspondence should be addressed to Jaejin Lee; jaejin@ajou.ac.kr
}

Received 12 April 2013; Revised 8 July 2013; Accepted 22 July 2013

Academic Editor: Sudhakar Nori

Copyright (C) 2013 Nguyen Dinh Lam et al. This is an open access article distributed under the Creative Commons Attribution License, which permits unrestricted use, distribution, and reproduction in any medium, provided the original work is properly cited.

\begin{abstract}
Conical frustums with quasihexagonal nanostructures are fabricated on an InGaP window layer of single junction GaAs solar cells using a polystyrene nanosphere lithography technique followed by anisotropic etching processes. The optical and photovoltaic characteristics of the conical frustum nanostructured solar cells are investigated. Reflectance of the conical frustum nanostructured solar cells is significantly reduced in a wide range of wavelengths compared to that of the planar sample. The measured reflectance reduction is attributed to the gradual change in the refractive index of the InGaP conical frustum window layer. An increase of $15.2 \%$ in the power conversion efficiency has been achieved in the fabricated cell with an optimized conical frustum nanostructure compared to that of the planar cell.
\end{abstract}

\section{Introduction}

Fresnel reflection of incident light comes from the large difference of refractive indexes at the interface between the two materials, especially for air and semiconductor materials. The high refractive index of III-V compound semiconductors such as InGaP and AlGaInP, materials which are utilized for the window layers in III-V solar cell applications, results in optical reflection loss up to $36 \%$ for the incident light. This severely limits the performance of solar cells based on III$\mathrm{V}$ materials. Therefore, to suppress the Fresnel reflection at the surface of the solar cells, effective antireflection coating (ARC) is introduced. The conventional multilayer ARCs are usually composed of a quarter wavelength stack of dielectrics with different refractive indices, such as $\mathrm{SiN}_{x}, \mathrm{SiO}_{2}, \mathrm{TiO}_{x}$, $\mathrm{MgF}_{2}$, and $\mathrm{ZnS}$ materials [1-4]. ARCs are usually fabricated by expensive processes such as plasma-enhanced chemical vapor deposition, electron beam evaporator, or sputtering. Under strong illumination in space or concentration applications, ARC has several problems such as mechanical and thermal stability, adhesion, and thermal mismatch. To overcome these issues, surface patterning with subwavelength structures is introduced as an alternative technique for reduction of incident light reflectance $[5,6]$.
Subwavelength structures can exhibit polarization insensitive, broadband, and omnidirectional antireflective characteristics [7-9]. That is due to the spatially graded structural profile in a single layer. In addition, the subwavelength structure can be robust and mechanically durable, making it particularly desirable for concentrator and space photovoltaic applications. Therefore, various cost-effective self-assembly techniques were employed to fabricate subwavelength nanostructures on different materials such as $\mathrm{Si}, \mathrm{GaAs}, \mathrm{Ge}$, and AlGaInP [10-13]. Cost-effective subwavelength structures may be fabricated by thermally dewetted $\mathrm{Au}, \mathrm{Ag}, \mathrm{Pt} / \mathrm{Pd}$, and $\mathrm{Ni}$ nanotemplates and thereafter pattern-transfer processes. However, their high dewetting temperature makes it difficult to apply this technique for the subwavelength structure fabrication on top of the III-V solar cells, and fabricated nanostructures tend to be in disorder. As has been well known, to form ohmic contacts, samples are usually heated by a rapid thermal annealing (RTA) process in range of 350 to $400^{\circ} \mathrm{C}$ for $30 \mathrm{~s}$. Performance of the solar cell devices will also be degraded by a deep diffusion of metal into the epitaxial layers at higher annealing temperature of $400^{\circ} \mathrm{C}$. Surface oxidation is also another issue when the samples are heated at high temperature for a long time. Increased surface recombination probability will result in the reduction 


\begin{tabular}{|c|c|c|}
\hline p-contact & $\mathrm{Ti} / \mathrm{Pt} / \mathrm{Au}$ & $500 \mathrm{~nm}$ \\
\hline p-ohmic & $\mathrm{p}^{+}-\mathrm{GaAs}$ & $300 \mathrm{~nm}$ \\
\hline Window & $\mathrm{p}^{+}-\mathrm{In}_{0.5} \mathrm{Ga}_{0.5} \mathrm{P}$ & $200 \mathrm{~nm}$ \\
\hline Emitter & $\mathrm{p}-\mathrm{GaAs}$ & $500 \mathrm{~nm}$ \\
\hline Base & $\mathrm{n}-\mathrm{GaAs}$ & $3,500 \mathrm{~nm}$ \\
\hline BSF & $\mathrm{n}^{+}-\mathrm{In}_{0.5} \mathrm{Ga}_{0.5} \mathrm{P}$ & $50 \mathrm{~nm}$ \\
\hline Buffer & $\mathrm{n}-\mathrm{GaAs}$ & $200 \mathrm{~nm}$ \\
\hline Substrate & $\mathrm{n}^{+}-\mathrm{GaAs}$ & $350 \mu \mathrm{m}$ \\
\hline $\mathrm{n}$-contact & $\mathrm{AuGe} / \mathrm{Ni} / \mathrm{Au}$ & $500 \mathrm{~nm}$ \\
\hline
\end{tabular}

FIGURE 1: Schematic of the fabricated single junction GaAs solar cell.

of photocurrent in solar cell devices. These issues may be overcome by antireflective disordered subwavelength nanostructures fabricated by using spin-coated Ag ink etched mask [14]. This technique is simple, low cost, and large-scale fabrication with a low sintered temperature (below $300^{\circ} \mathrm{C}$ ) that may avoid the metal diffusion and surface oxidation issues. The nanosphere lithography technique is also introduced and has attracted lots of attentions as one of the promising cost-effective subwavelength structure fabrication methods for the solar cell applications. In this technique, polystyrene and silica nanoparticles are usually utilized, and a shadow mask can be formed on the surface of the substrates with a hexagonal geometry without any annealing process $[15,16]$.

Many researchers have investigated the optical properties of the subwavelength structures for solar cell applications so far [11-13], but only a few publications report directly on the solar cell devices $[15,17]$. Although subwavelength structures are suitable for suppression of optical reflection loss in solar cell applications, direct influences of subwavelength structures and fabricated parameters on the performances of solar cell still need to be further investigated. In this work, conical frustums with the quasihexagonal nanostructures are fabricated on the InGaP window layer of the single junction GaAs solar cells using a polystyrene nanosphere lithography technique followed by anisotropic etching processes. The conical frustum nanostructures are varied by diameter and height of the nanoconical frustums. The optical and photovoltaic characteristics of the conical frustum nanostructured solar cells are investigated.

\section{Experiments}

The single junction GaAs solar cell structure is grown on n-type GaAs substrates in a low-pressure metalorganic chemical vapor deposition (MOCVD) reactor. The structure consists of a $0.2 \mu \mathrm{m}$-thick GaAs buffer, a $0.05 \mu \mathrm{m}$-thick InGaP back surface field (BSF), a $3.5 \mu \mathrm{m}$-thick GaAs base, a $0.5 \mu \mathrm{m}$-thick GaAs emitter, a $0.2 \mu \mathrm{m}$-thick $\mathrm{InGaP}$ window, and a $0.3 \mu \mathrm{m}$-thick GaAs cap layers, as shown in Figure 1. Photolithography, metal deposition, rapid thermal annealing, and wet chemical etch processes are applied for the solar cell fabrication. The metal structures are deposited by an ebeam evaporator and annealed by a rapid thermal annealing system. The $\mathrm{p}^{+}-\mathrm{GaAs}$ cap layer is selectively etched in a citric acid solution $\left(\mathrm{CA}: \mathrm{H}_{2} \mathrm{O}_{2}: \mathrm{H}_{2} \mathrm{O}=25: 1: 75\right)$. The solar cells are separated by a dicing saw system. The aperture area of the fabricated solar cell is $0.25 \mathrm{~cm}^{2}$.

The InGaP conical frustum nanostructures are fabricated using a nanosphere lithography technique. A monolayer of self-assembled polystyrene (PS) nanospheres with $2 \mathrm{wt} \%$ dispersion in isopropanol (IPA) is spin-cast onto the surface of solar cells. By tuning the degree of hydrophilicity, spinning speed, and the mixture concentration, a nearly-close-packed PS nanosphere monolayer is obtained on the surface of the solar cell (Figure 2(a)). In this work, PS nanospheres (Sigma Aldrich) with a diameter of $500 \mathrm{~nm}$ are chosen. After steady air drying for 15 minutes, the samples as shown in Figure 2(a) are short baked at $80^{\circ} \mathrm{C}$ for 10 minutes to increase the adhesion of PS nanospheres to the solar cell surfaces. The diameter of PS nanospheres can be tuned by oxygen reactive ion etching (RIE) plasma process, where a reactive gas $\mathrm{O}_{2}$ of $30 \mathrm{sccm}$ is introduced with an RF power of $100 \mathrm{~W}$, under a 10 mTorr pressure. Therefore, the diameter of the PS nanospheres is varied from 230 to $500 \mathrm{~nm}$. The conical frustum nanostructures are formed on the InGaP window layer of the solar cells by an inductively coupled plasma reaction ion etching (ICP-RIE) system. The ICP-RIE system is operated with a $200 \mathrm{~W}$ ICP and $50 \mathrm{~W}$ RF power at a chamber pressure of $10 \mathrm{mTorr}$. The samples are etched in a gas mixture of $5 \mathrm{sccm} \mathrm{BCl}_{3}$ and $30 \mathrm{sccm} \mathrm{Cl}_{2}$ plasma. The gas mixture is controlled through the individual electronic mass flow controllers. After dry etching, residuals of the PS nanospheres are lifted-off by dipping into the pure toluene solution for 20 minutes at room temperature and then cleaned by acetone, isopropanol, and deionized water in succession. The sample without the InGaP conical frustum nanostructure is used as a reference solar cell for comparison purpose. The InGaP conical frustum nanostructure geometry is investigated using a field emission scanning electron microscopy (FE-SEM). The loss of incident light is evaluated by reflectance spectra from 300 to $900 \mathrm{~nm}$ which are measured using an UVVis-NIR Cary 5000 Spectrometer. The photovoltaic current density-voltage $(J-V)$ characteristics of the GaAs solar cells are determined by a solar simulator under 1 sun air mass $1.5 \mathrm{G}$ at room temperature. The photocurrent response of the fabricated cells is also investigated at room temperature using a quantum efficiency measurement system (PV Measurements: QEX7).

\section{Results and Discussions}

The SEM images of the fabricated InGaP conical frustum nanostructures on the window layer of the single junction GaAs solar cells are shown in Figures 2(b), 2(c), 2(d), $2(\mathrm{e})$, and 2(f). The InGaP conical frustum nanostructures can be formed in the quasihexagonal geometry. The height and shape of the InGaP conical frustum nanostructures can be controlled by varying the etching duration and the 


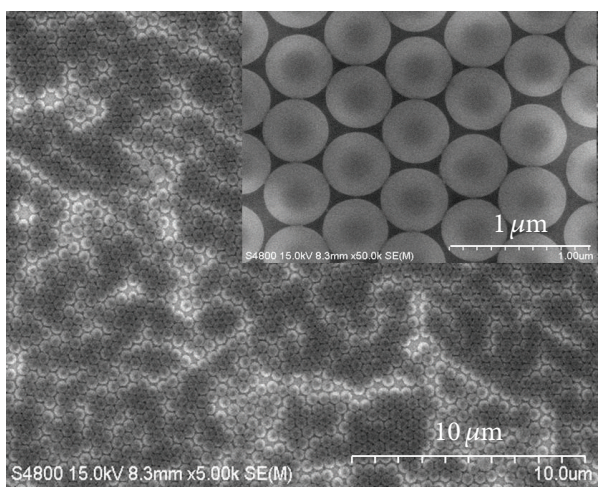

(a)

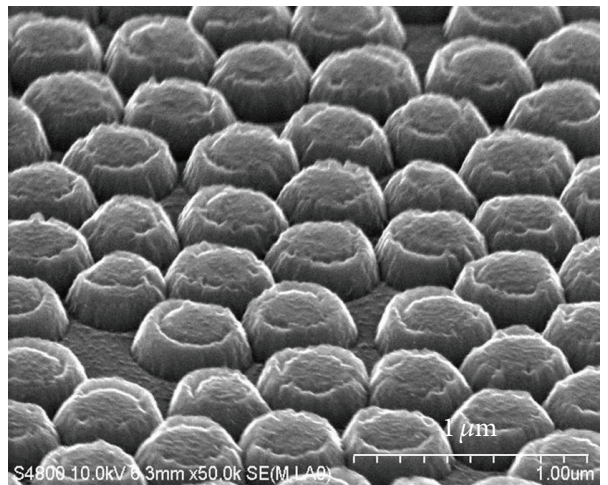

(c)

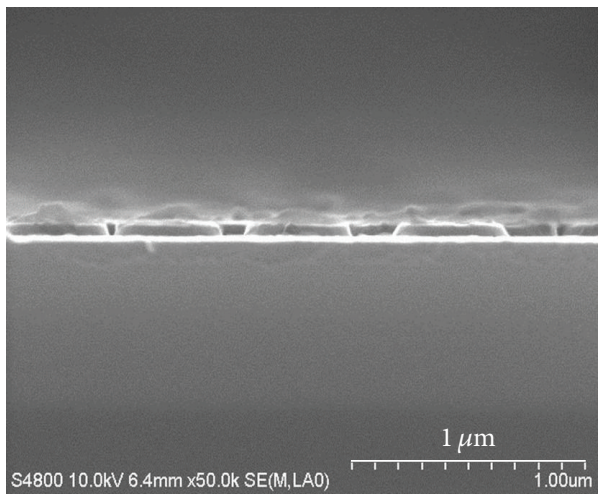

(e)

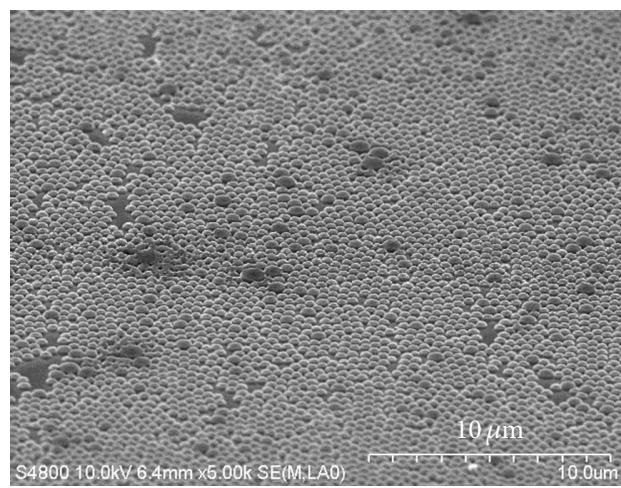

(b)

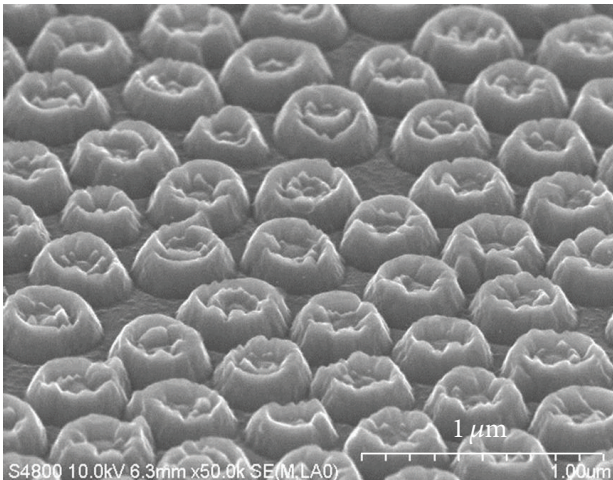

(d)

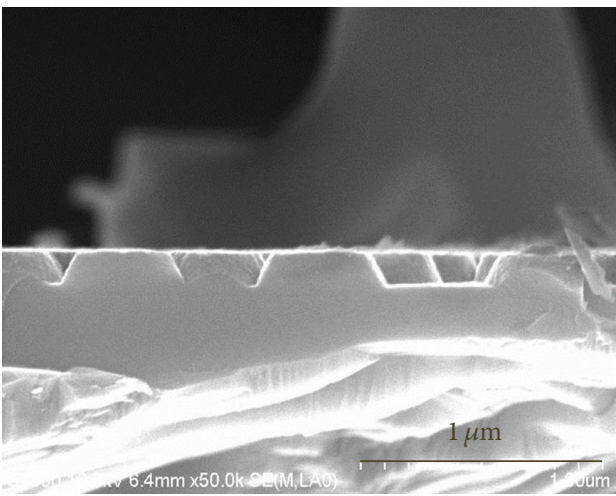

(f)

FIGURE 2: (a) SEM images of polystyrene nanospheres coated on the surface of the sample; (b) the conical frustum nanostructure fabricated on the InGaP window layer; (c) and (d) the conical frustum nanostructures fabricated by nanosphere particles with a top diameter of 380 and $300 \mathrm{~nm}$, respectively. SEM images of the $380 \mathrm{~nm}$ top diameter conical frustum nanostructures with height of (e) $60 \mathrm{~nm}$ and (f) $140 \mathrm{~nm}$.

PS nanosphere thinning process. Conical frustum nanostructures with four different top diameter, that is, $450 \mathrm{~nm}$, $300 \mathrm{~nm}$ (Figure 2(c)), $300 \mathrm{~nm}$ (Figure $2(\mathrm{~d})$ ), and $200 \mathrm{~nm}$, are fabricated on the InGaP window layer. To investigate the influence of the height of the conical frustum on the performances of the GaAs solar cells, the top diameter of the conical frustum is kept at a constant value of $380 \mathrm{~nm}$ while the height of the conical frustum is varied from $60 \mathrm{~nm}$ (Figure 2(e)) to $140 \mathrm{~nm}$ (Figure 2(f)). Figure 3 shows the total reflectance spectra and external quantum efficiency (EQE) of the GaAs solar cells with and without the InGaP conical frustum nanostructures. The optical reflection loss can be reduced in the whole measured wavelength range as the height of conical frustum nanostructure increases. Two main reasons have been applied to explain the suppression of surface reflectance by the fabricated nanostructure. Firstly, incident light will be redistributed when the spacing of the protuberances is larger than the wavelengths of incident light. Secondly, there is a gradual change in the refractive index, resulting in the Fresnel reflection suppression, when wavelengths of incident light are larger than the spacing of the protuberances [18]. The external quantum efficiency (EQE), 


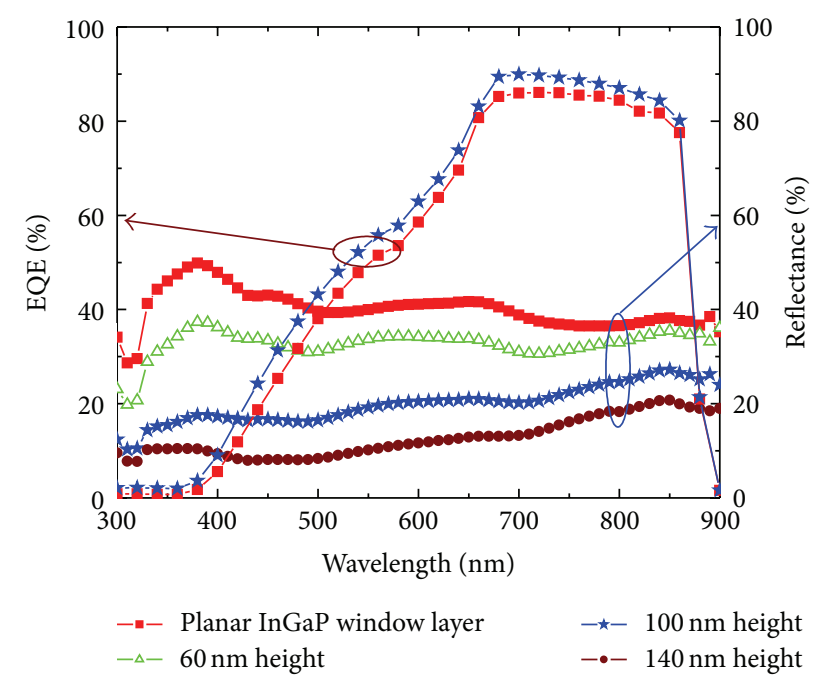

FIGURE 3: Reflectance and external quantum efficiency spectra of the fabricated samples. The height of the conical frustum nanostructures is varied from 60 to $140 \mathrm{~nm}$ while the top diameter is kept as a constant value of $380 \mathrm{~nm}$.

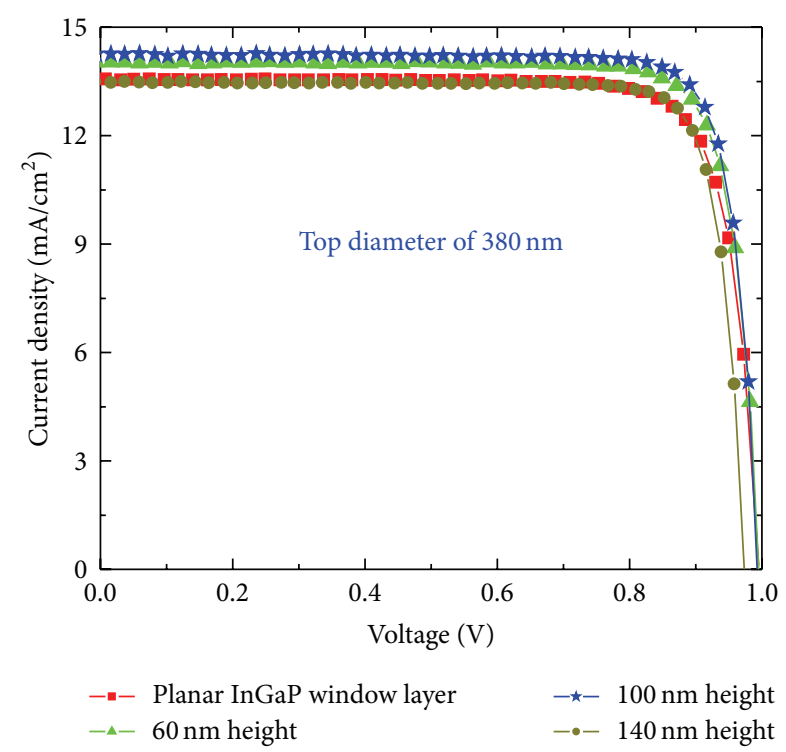

FIGURE 4: J-V curves of the planar and the patterned GaAs solar cells with a variation of the nanoconical frustum height.

defined as the number of elementary charges collected at the contacts divided by the number of photons impinging on the device, is also characterized for both devices, the planar sample and the conical frustum nanostructured sample with a height of $100 \mathrm{~nm}$. The suppression of the Fresnel reflection contributes to the enhanced optical absorption, which is also reflected in the EQE characteristics. The improvement of the photocurrent response is caused by an excess carrier generation in the p-n junction of the single junction GaAs solar cells resulting from improved light absorption. However, the EQEs of both fabricated samples in the shorter wavelength range of $680 \mathrm{~nm}$ are lower than those of the conventional
TABLE 1: Current density-voltage characteristics of the GaAs solar cells with various heights of the InGaP conical frustum nanostructure. The top diameter is kept as a constant value of $380 \mathrm{~nm}$.

\begin{tabular}{lcccc}
\hline Sample & $V_{\text {oc }}(\mathrm{V})$ & $J_{\text {sc }}\left(\mathrm{mA} / \mathrm{cm}^{2}\right)$ & FF (\%) & Eff. (\%) \\
\hline Planar cell & 0.996 & 13.558 & 83.04 & 11.08 \\
$60 \mathrm{~nm}$ & 0.995 & 14.030 & 83.46 & 11.66 \\
$100 \mathrm{~nm}$ & 0.993 & 14.242 & 84.52 & 11.95 \\
$140 \mathrm{~nm}$ & 0.973 & 13.477 & 84.84 & 11.13 \\
\hline
\end{tabular}

GaAs solar cells with a thin InGaP window layer [19]. It indicated that the absorbed light in the thick InGaP window layer in the fabricated solar cell structure does not contribute to the collected photocurrent. To overcome this issue, higher bandgap materials such as AlInP should be used as a window layer material.

The photovoltaic characteristics of the GaAs solar cell are dependent on the height of the conical frustum nanostructures, as can be seen in Figure 4. The short circuit current density $\left(J_{\mathrm{sc}}\right)$ changes a lot compared to the other parameters such as open circuit voltage $\left(V_{\text {oc }}\right)$ and fill factor (FF). The highest short circuit current density can be obtained when the height of the conical frustum is $100 \mathrm{~nm}$ (Table 1). When the height of conical frustum is more than $100 \mathrm{~nm}$, in spite of the lower optical reflectance, the short circuit current density is degraded. Besides that, $V_{o c}$ is slightly decreased as the height of conical frustum increases. It means that $\mathrm{p}$ $\mathrm{n}$ junction of the GaAs solar cell will be further degraded if the etching time is too long. That may be caused by the plasma induced damage in the anisotropic etching process [20]. The nature of this damage is a complex function of many plasma characteristics such as the chemistry of plasma gas, plasma energy, temperature, and pressure. Furthermore, surface damage causes significant enhancement of carrier recombination, resulting in the reduction of the photocurrent response. Therefore, there is a trade-off between the optical reflection loss reduction and the plasma induced damage in the conical frustum nanostructures fabricated on the InGaP window layer of the GaAs solar cells. In addition, as the height of the conical frustum increases, the surface area of the GaAs solar cell will become larger. This will result in a higher probability of surface oxidation and recombination. To relieve the effect of the surface recombination, geometrical designs of nanostructures have to be optimized in the first place to take advantage of the optical reflection loss reduction and carrier collection enhancement without significant increase of the surface recombination. And, on the other hand, surface passivation technique can be applied on nanostructures to reduce the surface recombination.

In order to investigate the influence of top diameter of the conical frustum on the characteristics of the GaAs solar cells, the height of the conical frustum is kept at a value of $100 \mathrm{~nm}$ while the top diameter of the conical frustum is varied from 200 to $450 \mathrm{~nm}$. $J-V$ curves and EQEs of the fabricated samples with the variation in the top diameter of the conical frustum are shown in Figures 5(a) and 5(b), respectively. The corresponding electrical parameters are summarized in Table 2. The characteristics of the GaAs solar cells are also 


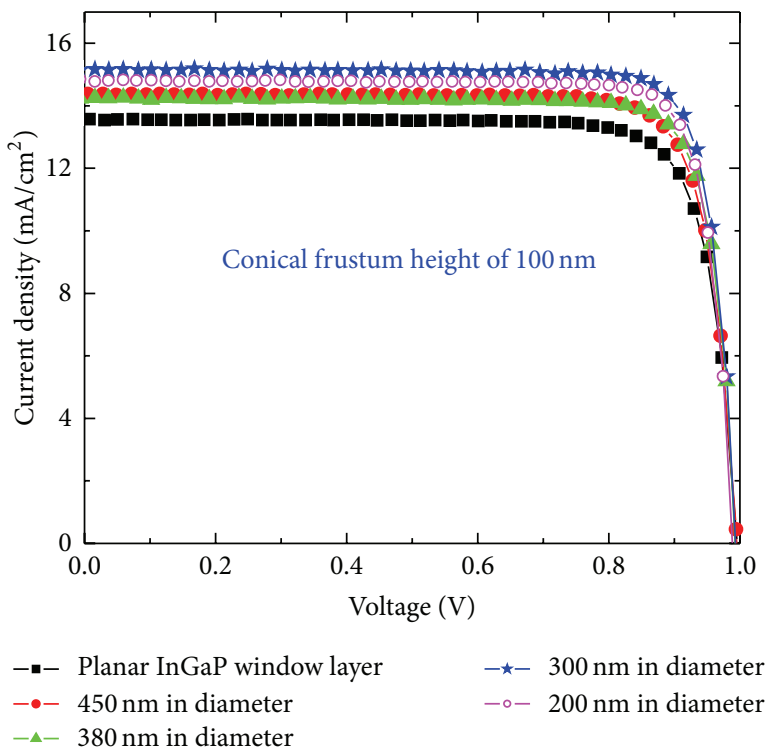

(a)

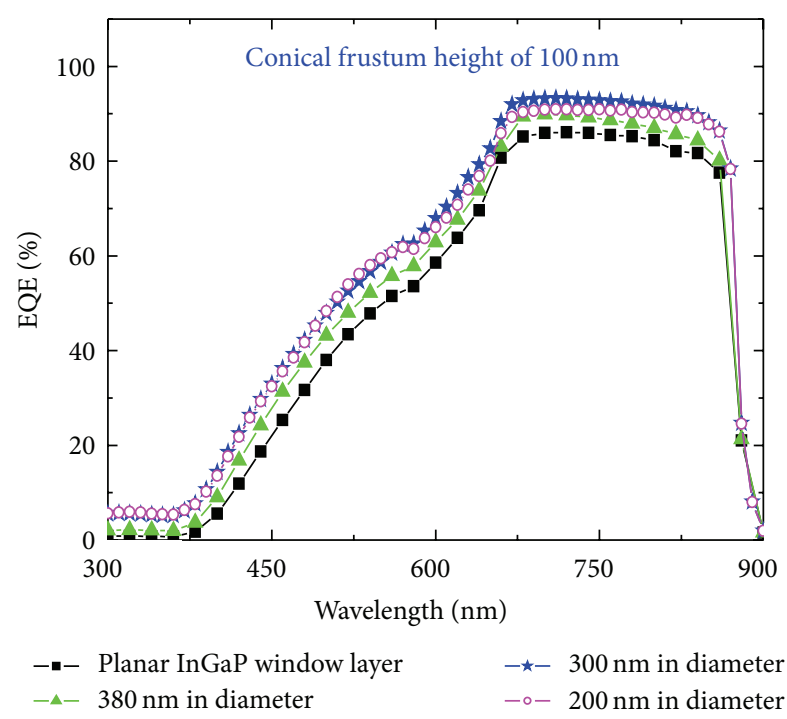

(b)

FIgURE 5: (a) $J$ - $V$ curves and (b) EQEs of the fabricated samples with the height of conical frustum of 100 nm and various top diameters of the InGaP conical frustum nanostructure.

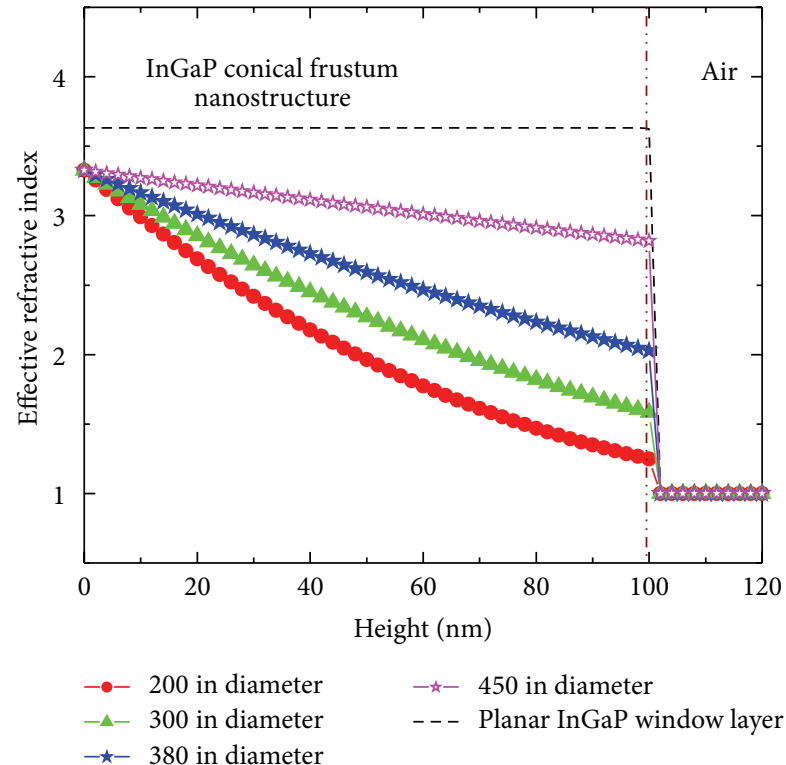

FIGURE 6: Change of the calculated effective refractive index at $\lambda=600 \mathrm{~nm}$ from the bottom of nanoconical frustum (height equals zero) to the solar cells surface with height of $100 \mathrm{~nm}$ with a variation in the top diameter of InGaP conical frustum nanostructures. The dashed line indicates the refractive index of bulk InGaP at the same wavelength.

dependent upon the top diameter of the conical frustum. The highest power conversion efficiency can be obtained when the top diameter of the conical frustum is $300 \mathrm{~nm}$, resulting in an increase of $15.2 \%$ in the power conversion efficiency of the sample with the InGaP conical frustum nanostructure compared to that of the planar InGaP window layer. The
TABLE 2: Current density-voltage characteristics of the GaAs solar cells with a height of conical frustum of $100 \mathrm{~nm}$ and various top diameters of the InGaP conical frustum nanostructure.

\begin{tabular}{lcccc}
\hline Sample & $V_{\text {oc }}(\mathrm{V})$ & $J_{\text {sc }}\left(\mathrm{mA} / \mathrm{cm}^{2}\right)$ & FF (\%) & Eff. (\%) \\
\hline Planar cell & 0.996 & 13.558 & 83.04 & 11.08 \\
$450 \mathrm{~nm}$ & 0.995 & 14.370 & 83.60 & 11.81 \\
$380 \mathrm{~nm}$ & 0.993 & 14.242 & 84.52 & 11.95 \\
$300 \mathrm{~nm}$ & 0.993 & 15.149 & 84.89 & 12.77 \\
$200 \mathrm{~nm}$ & 0.988 & 14.828 & 84.85 & 12.44 \\
\hline
\end{tabular}

degradation of the current density and EQE, when the top diameter of the conical frustum is $200 \mathrm{~nm}$, may be caused by the oxidation of the In GaP window layer because it is exposed to the high temperature in oxygen gas environment during the PS nanoparticle thinning process. Furthermore, open circuit voltage is further degraded when the top diameter of the conical frustum is reduced.

The broadband antireflection properties of the InGaP conical frustum nanostructures can be further understood by mapping the calculated effective refractive index at a wavelength of $600 \mathrm{~nm}$ across the height of $100 \mathrm{~nm}$ conical frustum [21], as shown in Figure 6. For the planar InGaP window layer, the refractive index changes sharply from air $\left(n_{\text {air }}=1\right)$ to $\operatorname{InGaP}\left(n_{\text {InGaP }}=3.62\right)$. While, for the InGaP conical frustum nanostructures, the refractive index changes gradually as the top diameter of conical frustum gets smaller. The refractive index gradient exhibited by the InGaP conical frustum nanostructures thus leads to a very low reflection over wide range of wavelengths. 


\section{Conclusions}

InGaP conical frustum nanostructures have been fabricated on top of the GaAs solar cells. The height and the top diameter of the InGaP conical frustum nanostructure variation effect on the solar cell characteristics, including the reflectance, external quantum efficiency, and current density-voltage curves, were measured and compared with those of the planar sample. An increase of $15.2 \%$ in the conversion efficiency is obtained at the optimal geometry with a $100 \mathrm{~nm}$ height and $300 \mathrm{~nm}$ top diameter of the InGaP conical frustum nanostructure. The improvements may be attributed to the gradual change in the refractive index, resulting in the Fresnel reflection suppression and light scattering effect by the In GaP conical frustum nanostructures.

\section{Acknowledgments}

This work was supported by the Converging Research Center Program through the National Research Foundation (NRF) of Korea funded by the Ministry of Education, Science and Technology (no. 2011K000590). This work was also supported by the New and Renewable Energy of the Korea Institute of Energy Technology Evaluation and Planning (KETEP) grant funded by the Korea in government, Ministry of Knowledge Economy (no. 20123010010110).

\section{References}

[1] C. H. M. van der Werf, H. D. Goldbach, J. Löffler et al., "Silicon nitride at high deposition rate by Hot Wire Chemical Vapor Deposition as passivating and antireflection layer on multicrystalline silicon solar cells," Thin Solid Films, vol. 501, no. 1-2, pp. 51-54, 2006.

[2] D. Li, F. Huang, and S. Ding, "Sol-gel preparation and characterization of nanoporous $\mathrm{ZnO} / \mathrm{SiO}_{2}$ coatings with broadband antireflection properties," Applied Surface Science, vol. 257, no. 23, pp. 9752-9756, 2011.

[3] G. Zhang, J. Zhao, and M. A. Green, "Effect of substrate heating on the adhesion and humidity resistance of evaporated $\mathrm{MgF}_{2} / \mathrm{ZnS}$ antireflection coatings and on the performance of high-efficiency silicon solar cells," Solar Energy Materials \& Solar Cells, vol. 51, no. 3-4, pp. 393-400, 1998.

[4] S.-M. Jung, Y.-H. Kim, S.-I. Kim, and S.-I. Yoo, "Design and fabrication of multi-layer antireflection coating for III-V solar cell," Current Applied Physics, vol. 11, no. 3, pp. 538-541, 2011.

[5] A. R. Parker and H. E. Townley, "Biomimetics of photonic nanostructures," Nature Nanotechnology, vol. 2, no. 6, pp. 347353, 2007.

[6] Y.-F. Huang, S. Chattopadhyay, Y.-J. Jen et al., "Improved broadband and quasi-omnidirectional anti-reflection properties with biomimetic silicon nanostructures," Nature Nanotechnology, vol. 2, no. 12, pp. 770-774, 2007.

[7] H. Sai, Y. Kanamori, K. Arafune, Y. Ohshita, and M. Yamaguchi, "Light trapping effect of submicron surface textures in crystalline Si solar cells," Progress in Photovoltaics: Research and Applications, vol. 15, no. 5, pp. 415-423, 2007.

[8] C. H. Chiu, P. Yu, H. C. Kuo et al., "Broadband and omnidirectional antireflection employing disordered GaN nanopillars," Optics Express, vol. 16, no. 12, pp. 8748-8754, 2008.
[9] Y. Kanamori, M. Sasaki, and K. Hane, "Broadband antireflection gratings fabricated upon silicon substrates," Optics Letters, vol. 24, no. 20, pp. 1422-1424, 1999.

[10] J. W. Leem and J. S. Yu, "Broadband and wide-angle antireflection subwavelength structures of Si by inductively coupled plasma etching using dewetted nanopatterns of Au thin films as masks," Thin Solid Films, vol. 519, no. 11, pp. 3792-3797, 2011.

[11] R. Y. Zhang, B. Shao, J. R. Dong et al., "Broadband quasiomnidirectional antireflection AlGaInP window for III-V multi-junction solar cells through thermally dewetted Au nanotemplate," Optical Materials Express, vol. 2, pp. 173-1182, 2011.

[12] J. W. Leem, Y. M. Song, and J. S. Yu, "Broadband antireflective germanium surfaces based on subwavelength structures for photovoltaic cell applications," Optics Express, vol. 19, no. 27, pp. 26308-26317, 2011.

[13] J. W. Leem, J. S. Yu, Y. M. Song, and Y. T. Lee, "Antireflective characteristics of disordered GaAs subwavelength structures by thermally dewetted Au nanoparticles," Solar Energy Materials \& Solar Cells, vol. 95, no. 2, pp. 669-676, 2011.

[14] C. I. Yeo, J. H. Kwon, S. J. Jang, and Y. T. Lee, "Antireflective disordered subwavelength structure on GaAs using spin-coated Ag ink mask," Optics Express, vol. 20, pp. 19554-19562, 2012.

[15] M.-Y. Chiu, C.-H. Chang, M.-A. Tsai, F.-Y. Chang, and P. Yu, "Improved optical transmission and current matching of a triple-junction solar cell utilizing sub-wavelength structures," Optics Express, vol. 18, no. 19, pp. A308-A313, 2010.

[16] K. Cho, D. J. Ruebusch, M. H. Lee et al., "Molecular monolayers for conformal, nanoscale doping of InP nanopillar photovoltaics," Applied Physics Letters, vol. 98, no. 20, Article ID 203101, 2011.

[17] Y. T. Lee, Y. M. Song, J. H. Jang, J. C. Lee, and E. K. Kang, "Disordered submicron structures integrated on glass substrate for broadband absorption enhancement of thin-film solar cells," Solar Energy Materials \& Solar Cells, vol. 101, pp. 73-78, 2012.

[18] Y. Li, J. Zhang, and B. Yang, "Antireflective surfaces based on biomimetic nanopillared arrays," Nano Today, vol. 5, no. 2, pp. 117-127, 2010.

[19] J. Pla, M. Barrera, and F. Rubinelli, “The influence of the InGaP window layer on the optical and electrical performance of GaAs solar cells," Semiconductor Science and Technology, vol. 22, no. 10, p. 1122, 2007.

[20] S. H. Zaidi, D. S. Ruby, and J. M. Gee, "Characterization of random reactive ion etched-textured silicon solar cells," IEEE Transactions on Electron Devices, vol. 48, no. 6, pp. 1200-1206, 2001.

[21] D. G. Stavenga, S. Foletti, G. Palasantzas, and K. Arikawa, "Light on the moth-eye corneal nipple array of butterflies," Proceedings of the Royal Society B, vol. 273, no. 1587, pp. 661-667, 2006. 

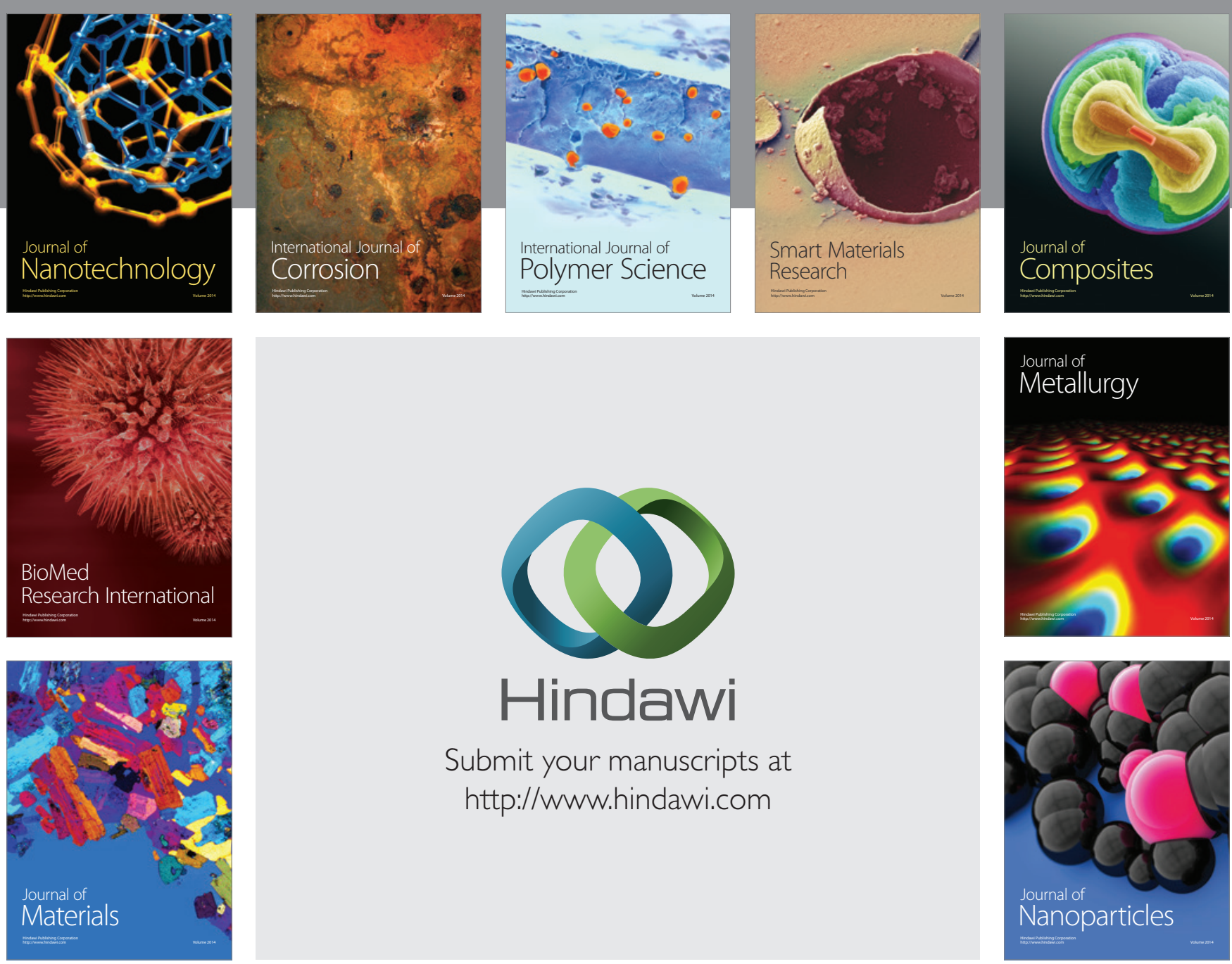

Submit your manuscripts at http://www.hindawi.com
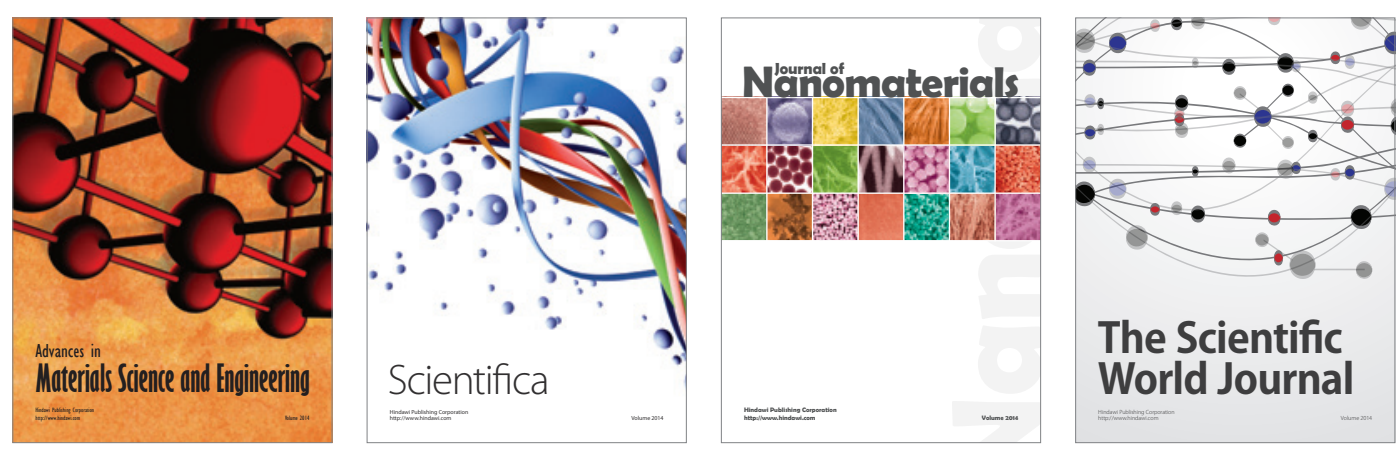

\section{The Scientific World Journal}
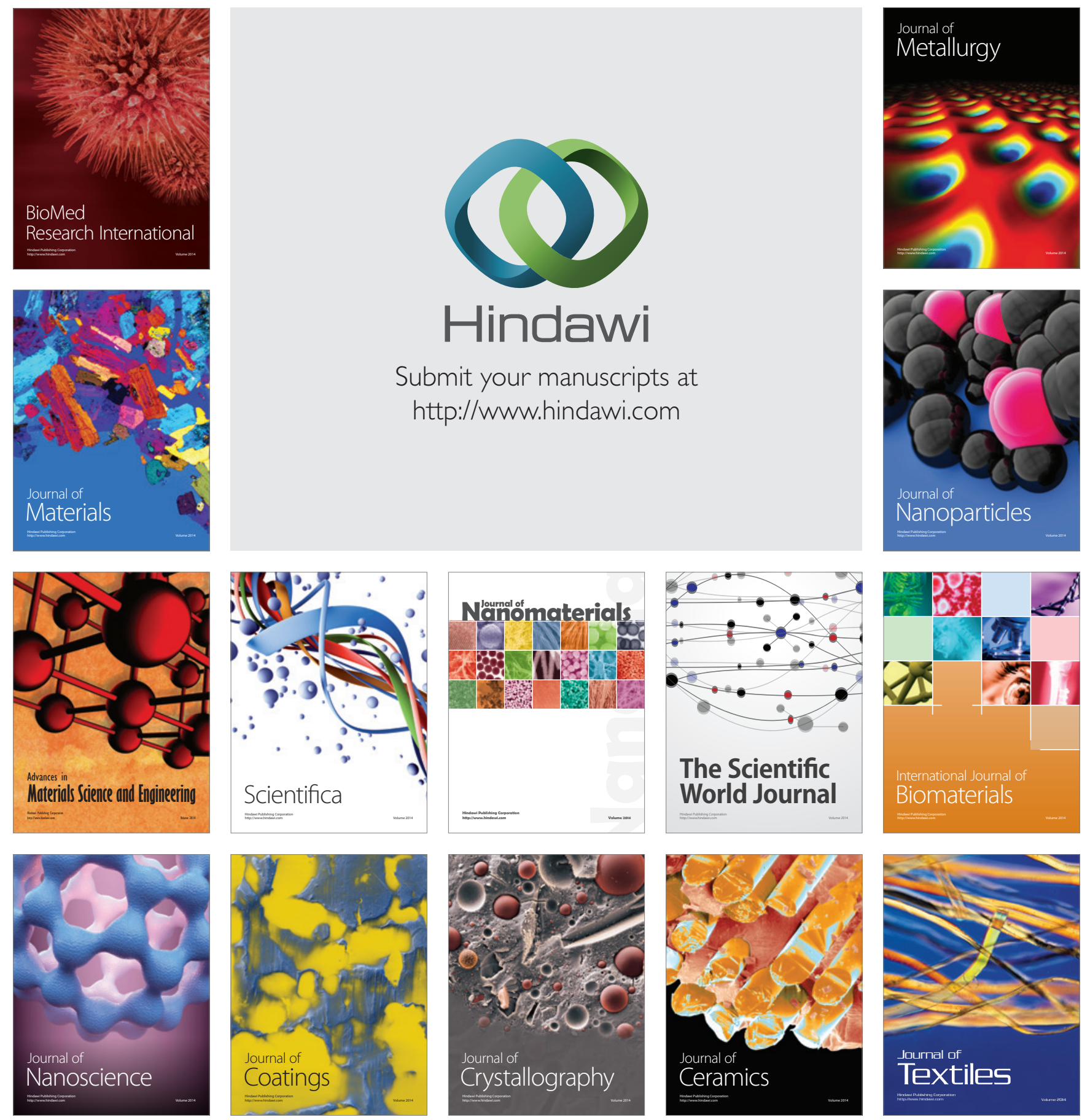